\title{
Correction to : Production of Lentiviral Particles
}

\section{Shuang Liu}

\section{Correction to:}

Chapter 12 in: Shuang Liu (ed.), Rheumatoid Arthritis:

Methods and Protocols, Methods in Molecular Biology, vol. 1868, https://doi.org/10.1007/978-1-4939-8802-0_12

\subsection{Production of Lentiviral Particles}

Unfortunately the book has been published with a Typo on Page no 125. This has been corrected to read as below

For each plate, mix $20 \mu \mathrm{g}$ Mission shRNA plasmid, $15 \mu \mathrm{g}$ psPAX2 plasmid, and $6 \mu \mathrm{g}$ pMD2.G plasmid by gently pipetting. Bring up to $500 \mu \mathrm{L}$ using autoclaved water. 